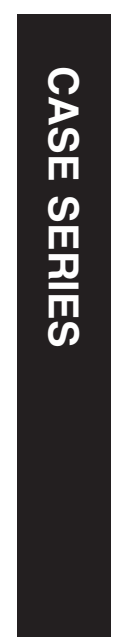

Department of

Ophthalmology, Shaare Zedek Medical Center, Jerusalem, Israel

Correspondence: K Brosh, Department of Ophthalmology, Shaare Zedek Medical Center, Eli Cohen $1 \mathrm{a}$, Jerusalem 92347, Israel

Tel: +972 507163004 ;

Fax: +972 26555184 .

E-mail: broshk@gmail.com

Received: 7 August 2013 Accepted in revised form: 25 March 2014

Published online: 2 May 2014

\section{High intraocular pressure in four vitrectomized eyes with intravitreal C3F8 without high altitude travel}

\begin{abstract}
Importance It is well known that altitude ascent with intravitreal gas can cause expansion of gas and intraocular pressure (IOP) elevation. According to Boyle's law, the gas bubble will not expand unless a higher altitude than the gas insertion site has been reached. We report four cases in which intravitreal gas was injected at an altitude of $790 \mathrm{~m}$ (Jerusalem). All four cases developed high IOP even though they did not reach a higher altitude in their post-operative period. Observations A report of four patients following vitrectomy with $12 \%$ mixture of perfluoropropane and air are presented. All four patients arrived with ocular pain following the ascent by car of 765-1100 $\mathrm{m}$ to Jerusalem where the vitrectomy and gas insertion was conducted. Upon examination, all four patients had high IOP (30$55 \mathrm{~mm} \mathrm{Hg}$ ). IOP was well controlled with IOP-lowering medications. None of the patients suffered from long-term complications.

Conclusions and Relevance Caution should be taken with altitude changes in patients with intravitreal gas even if there was no ascent from the altitude in which the vitrectomy was performed.
\end{abstract}

Eye (2014) 28, 892-894; doi:10.1038/eye.2014.83; published online 2 May 2014

\section{Introduction}

It is well known that air travel should be avoided in the post-operative period of vitrectomized eyes with intravitreal gas. ${ }^{1,2}$ According to Boyle's law $\left(\mathrm{P}_{1} \mathrm{~V}_{1}=\mathrm{P}_{2} \mathrm{~V}_{2}\right)$, ascent to a higher altitude causes expansion of a intravitreal gas which can lead to increase in intraocular pressure (IOP). ${ }^{3}$ However, minor altitudinal changes are usually tolerated by the vitrectomized eye with intravitreal gas due to compensatory mechanisms. ${ }^{4}$ Therefore, the standard of care advised by retinal surgeons is to avoid flights and high altitude ascent as long as there is intraocular gas present. We report four patients with intravitreal gas who developed elevated IOP due to moderate altitude descent followed by equivalent altitude ascent. To the best of our knowledge, this is the first report of high IOP with intravitreal gas without any altitude ascent from the place where the gas was inserted.

\section{Case description}

In the past 10 years, we have treated four patients who had undergone intravitreal perfluoropropane injection and developed severe IOP elevation associated with altitude ascent. All four patients suffered from retinal detachment and underwent pars plana vitrectomy with suture-less sclerotomy. All the operations were performed at the Shaare Zedek Medical Center, Jerusalem, which is located $790 \mathrm{~m}$ above the sea level. Following pars plana vitrectomy and retinal laser photocoagulation, fluid-gas exchange with $12 \%$ mixture of perfluoropropane with air was performed. The patients were discharged to their home towns with an intravitreal gas bubble.

\section{Cases 1 and 2}

The patients lived in Jerusalem but visited a lower altitude during the early post-operative period. On their way back to Jerusalem, there is 
a section with a rapid elevation of $500 \mathrm{~m}$. This section rate of ascent is approximately $40 \mathrm{~m} / \mathrm{min}$ by car. Following the ascent, the patients arrived to ophthalmic emergency room with ocular pain and IOP elevation.

\section{Cases 3 and 4}

Both patients lived at a lower altitude than the hospital so the patients came to each follow-up after altitude ascent. Patient 3 arrived to the emergency room with ocular pain and high IOP after the same ascent to Jerusalem as described above. The 4th patient was seen at the hospital outpatient clinic with recurrent IOP spikes on each follow-up visit. Each IOP spike was after ascent of $1100 \mathrm{~m}$ at a rate of approximately $35 \mathrm{~m} / \mathrm{min}$. He was under treatment with three IOP-lowering medications.

In all the patients, IOP-lowering medications were given immediately in order to help normalize the IOP. This, and the continued stay at the same altitude allowed for the return to normal IOP in all patients within approximately $1 \mathrm{~h}$. Case details are shown in Table 1.

\section{Discussion}

In all four patients, the bubble of gas was inserted in a hospital located in Jerusalem $(795 \mathrm{~m})$, therefore according to Boyle's law, upon returning to Jerusalem after altitude changes the size of the gas bubble should be the same as before altitude changes. In all the patients, IOP was elevated after the altitude ascent implying some other mechanism may be involved. This phenomenon has been described in previous study on rabbits exposed to hyperbaric enviroment. ${ }^{5}$ Two possible explanations are
(1) larger volume of aqueous by hypotony prevention mechanism or (2) gas bubble enlargement by diffusion of particles in hyperbaric environment into the bubble. In our opinion, the former mechanism is more likely as the gas bubble did not expand in the aforementioned hyperbaric report. ${ }^{5}$ In order to prevent ocular hypotony at lower altitude, self-regulatory mechanisms fill the eye with aqueous humor. ${ }^{5}$ Previously Johnstone et $a l^{6}$ showed trabecular meshwork collapse at low IOP, which increases aqueous volume in the eye. However, upon altitude ascent, the gas bubble expands to the same size as when it was at hospital discharge, but with a larger volume of aqueous, therefore the IOP rises. Furthermore, self-compensatory mechanisms which include choroidal compression, sclera expansion, and increased aqueous outflow $^{4}$ need time to fully accommodate. ${ }^{3,4}$ Therefore, a rapid rate of ascent can overcome the compensatory mechanisms and can induce high IOP and pain.

If a moderate altitude ascent is inevitable during the post-operative period, the physician should recommend the following:

1. Prescribing prophylactic medication for IOP control before the ascent.

2. Recommending gradual ascent with multiple stops.

3. Immediate descent in case of ocular pain or vision loss.

4. Consider modifying the amount of gas placed, based on the change of the altitude that the patient will experience and the post-operative period that this changes will take place.

The decision whether to allow patients after vitrectomy with intravitreal gas to travel to a higher

Table 1 Summarized data of four patients with IOP elevation following altitude ascent

\begin{tabular}{|c|c|c|c|c|c|c|c|c|}
\hline Patient & $\begin{array}{l}\text { Altitude of } \\
\text { habitation } \\
\text { place }(m)\end{array}$ & $\begin{array}{l}\text { Altitude of the } \\
\text { lowest spot on his } \\
\text { route }(m)^{\mathrm{a}}\end{array}$ & $\begin{array}{c}\text { Altitude } \\
\text { ascent }(m)\end{array}$ & $\begin{array}{c}\text { Approximate highest } \\
\text { rate of altitude ascent } \\
(\mathrm{m} / \mathrm{min})\end{array}$ & $\begin{array}{c}\text { Gas bubble } \\
\text { size (\%) }\end{array}$ & $\begin{array}{c}\text { Post-operative } \\
\text { day }\end{array}$ & $\begin{array}{c}\text { Intraocular } \\
\text { pressure after } \\
\text { ascent }^{\mathrm{b}}\end{array}$ & Lens \\
\hline 1 & $790^{c}$ & 20 & 770 & 40 & 70 & 13 & 55 & $\begin{array}{l}\text { Pseudo } \\
\text { phake }\end{array}$ \\
\hline 2 & $790^{c}$ & 0 & 790 & 40 & 55 & 4 & 46 & Phake \\
\hline \multirow[t]{3}{*}{3} & 395 & 25 & 765 & 40 & 80 & 4 & 40 & $\begin{array}{l}\text { Pseudo } \\
\text { phake }\end{array}$ \\
\hline & & & & & 60 & 15 & 27 & \\
\hline & & & & & 40 & 29 & 18 & \\
\hline \multirow[t]{4}{*}{4} & 240 & $\begin{array}{c}-310 \\
\text { Dead sea }\end{array}$ & 1100 & 35 & 70 & 12 & $36^{\mathrm{d}}$ & Phake \\
\hline & & & & & 65 & 16 & $40^{\mathrm{d}}$ & \\
\hline & & & & & 60 & 19 & $50^{\mathrm{d}}$ & \\
\hline & & & & & 50 & 26 & $20^{\mathrm{d}}$ & \\
\hline
\end{tabular}

\footnotetext{
a The highest spot on the route of all patients was Jerusalem $(790 \mathrm{~m})$.

${ }^{\mathrm{b}}$ All IOP examinations were done at Jerusalem $(790 \mathrm{~m})$.

${ }^{\mathrm{c}}$ Lived in Jerusalem.

${ }^{\mathrm{d}}$ The patient was under medications for lowering intraocular pressure.
} 
altitude should be on a case to case basis, considering the amount of altitude change, the size of the gas bubble, the rate of altitude ascent, and glaucoma status. All patients should be informed that in case of pain or visual loss in an eye with a gas bubble, immediate ophthalmologic examination should be undertaken. As a general rule, patients should avoid as possible, rapid altitude elevation even if a similar descent was done in the post-operative period without any discomfort.

\section{Summary}

What was known before

- High altitude travel or flight of patients with intravitreal gas may cause gas expansion and high IOP.

What this study adds

- High IOP can be caused by altitude changes in patients with intravitreal gas even if there was no ascent from the altitude in which the vitrectomy was performed.

\section{Conflict of interest}

The authors declare no conflict of interest.

\section{References}

1 Lincoff $\mathrm{H}$, Weinberger D, Stergiu P. Air travel with intraocular gas. II. Clinical considerations. Arch Ophthalmol 1989; 107(6): 907-910.

2 Mills MD, Devenyi RG, Lam WC, Berger AR, Beijer CD, Lam SR. An assessment of intraocular pressure rise in patients with gas-filled eyes during simulated air flight. Ophthalmology 2001; 108(1): 40-44.

3 Amini R, Barocas VH, Kavehpour HP, Hubschman JP. Computational simulation of altitude change-induced intraocular pressure alteration in patients with intravitreal gas bubbles. Retina 2011; 31(8): 1656-1663.

4 Lincoff H, Weinberger D, Reppucci V, Lincoff A. Air travel with intraocular gas. I. The mechanisms for compensation. Arch Ophthalmol. 1989; 107(6): 902-906.

5 Jackman SV, Thompson JT. Effects of hyperbaric exposure on eyes with intraocular gas bubbles. Retina 1995; 15(2): 160-166.

6 Johnstone MA, Grant WG. Pressure-dependent changes in structures of the aqueous outflow system of human and monkey eyes. Am J Ophthalmol. 1973; 75(3): 365-383. 